BMJ Open Diabetes Research \& Care

\title{
Glycemic variability and cardiovascular disease in patients with type 2 diabetes
}

\author{
Marcela Martinez, ${ }^{1}$ Jimena Santamarina, ${ }^{1}$ Adrian Pavesi, ${ }^{2}$ Carla Musso, ${ }^{2}$ \\ Guillermo E Umpierrez (iD) ${ }^{3}$
}

To cite: Martinez M, Santamarina J, Pavesi A, et al. Glycemic variability and cardiovascular disease in patients with type 2 diabetes. BMJ Open Diab Res Care 2021;9:e002032. doi:10.1136/ bmjdrc-2020-002032

Received 22 November 2020 Revised 7 January 2021 Accepted 7 February 2021
Check for updates

C Author(s) (or their employer(s)) 2021. Re-use permitted under CC BY-NC. No commercial re-use. See rights and permissions. Published by BMJ.

${ }^{1}$ Diabetes and Metabolism, Favaloro Foundation University Hospital, Buenos Aires, Federal District, Argentina

${ }^{2}$ Diabetes and Endocrinology, Favaloro Foundation University Hospital, Buenos Aires, Federal District, Argentina ${ }^{3}$ Medicine, Emory University, Atlanta, Georgia, USA

Correspondence to Professor Guillermo E Umpierrez; geumpie@emory.edu

\section{ABSTRACT}

Glycated hemoglobin is currently the gold standard for assessment of long-term glycemic control and response to medical treatment in patients with diabetes. Glycated hemoglobin, however, does not address fluctuations in blood glucose. Glycemic variability (GV) refers to fluctuations in blood glucose levels. Recent clinical data indicate that GV is associated with increased risk of hypoglycemia, microvascular and macrovascular complications, and mortality in patients with diabetes, independently of glycated hemoglobin level. The use of continuous glucose monitoring devices has markedly improved the assessment of GV in clinical practice and facilitated the assessment of GV as well as hypoglycemia and hyperglycemia events in patients with diabetes. We review current concepts on the definition and assessment of GV and its association with cardiovascular complications in patients with type 2 diabetes.

\section{INTRODUCTION}

Diabetes is a serious chronic disease with a prevalence of $9.3 \%$ in adults aged $20-79$ years, and the global projection shows an increase of more than $50 \%$ in the next 25 years in the USA. ${ }^{1}$ People with diabetes have two to three times higher probability of developing cardiovascular disease and death compared with individuals without diabetes. The life expectancy is reduced to 6-7 years in people with diabetes over 40 years of age, and this reduction is doubled in patients with established cardiovascular disease. ${ }^{2-5}$

Glycated hemoglobin (HbAlc) is currently the gold standard for assessment of glycemic control and response to therapy in patients with type 1 (T1D) and type 2 (T2D) diabetes. During the past three decades, a large number of epidemiological studies have shown that high HbA1c is an important risk indicator of diabetic complications. In addition, several studies have reported that reduction in $\mathrm{HbAlc}$ is associated with a significant reduction in microvascular complications (retinopathy, nephropathy and neuropathy), as well as decreased cardiovascular risk and diabetes-related mortality. ${ }^{6-9}$ Based on these studies, major diabetes organizations have set treatment goals of $\mathrm{HbAlc}$ ranging from
$6.5 \%$ to $7.5 \%$ for most patients with diabetes depending on the presence of complications, risk of hypoglycemia, life expectancy, disease duration, patient preferences, and available resources. ${ }^{10-12}$

While HbA1c reflects previous 3-month glycemic control, it does not address shortterm glycemic variability (GV) or daily fluctuations in blood glucose levels or hypoglycemic events. In recent years, the importance of considering GV when optimizing treatment regimens has received increasing interest in clinical practice. ${ }^{13}$ High GV has been associated with increased risk of hypoglycemia, ${ }^{13-16}$ reduced patient psychological well-being and quality of life, ${ }^{17}$ and increased risk of cardiovascular disease ${ }^{18-20}$ and mortality in patients with T2D. ${ }^{21-23}$ Although the underlying mechanisms are not completely understood, increasing evidence indicates that daily fluctuations in blood glucose are associated with endothelial dysfunction, ${ }^{23-25}$ inflammation and oxidative stress, ${ }^{22} 24$ factors associated with the pathogenesis of vascular damage and atherosclerosis.

There is currently no consensus on the use of metrics to assess GV. The use of capillary blood glucose testing by self-monitored blood glucose (SMBG) and continuous glucose monitoring (CGM) represent useful tools to assess GV to help clinicians and patients overcome the limitations of $\mathrm{HbAlc}$ in diabetes management. In this review, we discuss the definition, assessment of GV and its association with cardiovascular complications in patients with T2D.

\section{DEFINITIONS AND METHODS OF ASSESSMENT Definition}

Glycemic variability refers to swings in blood glucose levels; it means the oscillations that occur throughout the day, including episodes of hypoglycemia and postprandial hyperglycemia. ${ }^{1326} 27$ Clinical data on GV assess shortterm-both intraday and day-to-day GV—as well as long-term GV based on fluctuations in 
blood glucose after weeks or months assessed by HbAlc, SMBG and CGM data.

The introduction of CGM sensors in 1999 revolutionized blood glucose monitoring and has provided a better way to assess GV in patients with diabetes. ${ }^{13} 2829$ CGM sensors measure interstitial glucose concentration every $1-5 \mathrm{~min}$, mitigating the need for multiple capillary SMBG and greatly increasing the information on glucose fluctuations and trends. ${ }^{22}$ The high number of glucose values throughout the day and night helps clinicians and individuals with diabetes to overcome the limitations of SMBG and HbA1c. The main CGM metrics reported with CGM use are time spent in the glycemic target range or time in range (TIR) of $70-180 \mathrm{mg} / \mathrm{dL}$, time above range $>180 \mathrm{mg} / \mathrm{dL}$, time spent below range or hypoglycemia $(<70 \mathrm{mg} / \mathrm{dL}$ and $<54 \mathrm{mg} / \mathrm{dL})$, and GV expressed as coefficient of variation (CV). Recently, several organizations published consensus statements on the role of CGM and the specific metrics to use for assessing overall glycemic management, hyperglycemia, hypoglycemia, and GV. ${ }^{30}$

There are three basic types of CGM devices: 'real-time' CGM devices, which continuously track glucose concentrations in the interstitial fluid; 'intermittent' CGM devices, which show continuous glucose measurements retrospectively at the time the patient or the physician checks the data; and 'diagnostic' CGM, which the patient is blinded to and is intended to inform the physician about the patient's blood glucose levels in their dayto-day lives. ${ }^{13}$ All three types of CGM provide detailed information about GV.

\section{Methods of GV assessment}

GV has emerged as an important tool in the evaluation of glycemic control, which may be a better predictor of complications than average glucose by SMBG and HbA1c values. $^{20} 2531 \mathrm{GV}$ metrics have been associated with microvascular complications s ${ }^{152} 33$ as well as increased risk of adverse cardiovascular outcomes in patients with diabetes. ${ }^{19} 21232534$ However, there are still unknown aspects regarding the relationships between GV and diabetes complications due to heterogeneity between studies, including the different metrics used to assess this parameter. Therefore, simplifying the assessment is an important aim for healthcare providers to be able to easily calculate and interpret the results.

\section{Short-term GV}

$\mathrm{CV}$ and SD are the more frequently used intraday GV measures. ${ }^{13} \mathrm{SD}$ is the rate of dispersion from average glycemia, and CV is the SD divided by the mean glucose. When averaging each daily SD or CV, the mean of within-day daily GV over the stated time period can be estimated. ${ }^{19}{ }^{26}$ Mean of daily differences (MODD), a metric for estimating the interday GV, is calculated as the absolute difference between two glucose values measured at the same time within a 24-hour interval. The higher the MODD score, the larger the interday GV. ${ }^{26}$ Mean amplitude glycemic excursion is a traditional measure that
Box 1 Standardized continuous glucose monitoring (CGM) metrics for clinical care

- Number of days CGM device is worn (recommend 14 days).

- Percentage of time CGM device is active (recommend $70 \%$ of data from 14 days).

- Mean glucose.

- Glucose management indicator.

- Glycemic variability $(\% \mathrm{CV})$ target $\leq 36 \%$ *

- Time above range: $\%$ of readings and time $181-250 \mathrm{mg} / \mathrm{dL}$ $(10.1-13.9 \mathrm{mmol} / \mathrm{L})$.

- Time in range: \% of readings and time $70-180 \mathrm{mg} / \mathrm{dL}$ $(3.9-10.0 \mathrm{mmol} / \mathrm{L})$.

- Time below range: \% of readings and time $54-69 \mathrm{mg} / \mathrm{dL}$ (3.0-3.8 mmol/L).

- Time below range: $\%$ of readings and time $<54 \mathrm{mg} / \mathrm{dL}$ ( $<3.0 \mathrm{mmol} / \mathrm{L})$.

*Some studies suggest that lower \%CV targets (<33\%) provide additional protection against hypoglycemia for those receiving insulin or sulfonylureas. Adapted from the American Diabetes Association Standards of Medical Care in Diabetes 2020 . $^{7}$

$\mathrm{CV}$, coefficient of variation.

takes into account glycemic peaks and nadirs during a day, but considers only fluctuations above 1 SD of average glycemia so it does not detect all the oscillations. ${ }^{135}$

Other metrics less commonly used are continuous overlapping net glycemic action, average daily risk range, low blood glucose index, glycemic risk assessment diabetes equation, high blood glucose index, mean absolute glucose, averaged glycemic profile, average real variability, root mean square error, variation independent of mean, and residual SD. ${ }^{26}$

With an increase in the use of CGM devices, different metrics have become increasingly used in routine clinical practice. Recently, the International Consensus on Time in Range defined glucose targets and the percentage readings within, below and above target range recommended. ${ }^{30}{ }^{36}$ TIR of blood glucose concentration between $70 \mathrm{mg} / \mathrm{dL}$ and $180 \mathrm{mg} / \mathrm{dL}(3.9-10 \mathrm{mmol} / \mathrm{L})$ has been popularized as an important metric to be derived from CGM data to classify glycemic management. ${ }^{30} 3637$

Reports can be generated from CGM that will allow the provider to determine TIR and to assess hypoglycemia, hyperglycemia, and GV (box 1).

The International Consensus on Use of Continuous Glucose Monitoring recommended CV as the preferred measure and considered SD as a secondary one, but clinicians should become familiar with both methods. ${ }^{37}$ The CV is calculated by dividing the SD by the mean glucose and multiplying by 100 to get a percentage. The SD represents the spread in glucose readings around the average or variation. The goal is the lowest SD possible, which would reflect a steady glucose level with minimal swings. The preference of using CV over SD is because $\mathrm{SD}$ is highly influenced by the mean glucose-someone with a higher mean glucose will have a higher SD. The $\mathrm{CV}$ corrects and normalizes $\mathrm{GV} \cdot{ }^{37}$ In addition, $\mathrm{CV}$ has the advantage of being a metric relative to the mean, which 
makes it more descriptive of hypoglycemic excursions than SD alone. Current recommendations target a CV of $36 \%$ or lower, which is considered a marker of 'stable' blood glucose concentration.

\section{Long-term GV}

Long-term GV considers fluctuations in blood glucose after weeks or months and could be assessed by measuring HbAlc or by long-term fasting and postprandial plasma glucose values determined by SMBG. Longterm GV has been reported in observational studies and meta-analyses to predict diabetic complications in both T1D and T2D. ${ }^{15} 192131$ The association between HbA1c variability by different metrics as $\mathrm{SD}$ and $\mathrm{CV}$ has been strongly associated with microvascular complications and increased cardiovascular disease, as well as increased allcause mortality, in patients with T2D. ${ }^{15-21} 31$ In these studies, long-term GV has shown to be a better predictor of adverse outcomes than the average HbAlc.

\section{GV and tissue damage}

Hyperglycemia increases the production of reactive oxygen species (ROS), which inactivates nitric oxide (NO), ${ }^{19} 38$ leading to endothelial dysfunction and vascular complications. In addition to sustained hyperglycemia, large fluctuating glucose values impact on changes in endothelial NO synthase. In vitro studies in human umbilical vein endothelial cells reported that increases in nitrotyrosine and 8-hydroxydeoxyguanosine, markers of oxidative stress, were more pronounced when they were exposed to intermittent high glucose than in constant high glucose. ${ }^{24}$ In addition, hyperglycemia triggers the activation of protein kinase $\mathrm{C}$ (PKC), which has an effect on vascular cell growth and apoptosis, extracellular matrix synthesis, and altered vascular homeostasis. ${ }^{24}{ }^{38} \mathrm{PKC}$ also increases production of ROS, which decreases $\mathrm{NO}$ availability and overproduction of vasoconstrictors such as endothelin-1 and cyclo-oxygenase-2 expression, molecules involved in platelet aggregation and vasoconstriction. ${ }^{39}$ The combination of reduced NO availability and increased vasoconstrictor production has been shown to play a role in the development of vascular atherosclerotic changes.

Hyperglycemia and PKC activation-induced ROS production result in inflammatory changes in the vascular endothelium including monocytes adhesion, formation of foam cells, and activation of major biochemical paths including polyol pathway flux and increased formation of advanced glycation end products, further contributing to the development of atherosclerosis. ${ }^{40}$ In addition, chronic hyperglycemia and exposure of endothelial cells to intermittent high glucose produce an overproduction of several adhesion molecules such as intracellular adhesion molecule-1, vascular cell adhesion molecule-1, and E-selectin, which regulate the adhesion of leukocytes to the endothelium, leading to atheroma pathogenesis. ${ }^{24} 38$

Increasing evidence indicates that high glucose fluctuations also increase oxidative stress in heart tissue and can induce cardiomyocyte apoptosis. In an animal model, Ying and colleagues ${ }^{41}$ evaluated markers of tissue oxidative stress in heart ventricles and found that blood glucose fluctuation accelerated cardiac injury via intracellular signal transduction pathways including protein kinase B (AKT), key enzyme in cell death.

\section{GV and clinical implications}

Diabetes is a leading cause of microvascular complications such as nephropathy, retinopathy and peripheral neuropathy. ${ }^{20233}$ It is also associated with an accelerating atherosclerosis and cardiovascular disease, ${ }^{21} 233442$ which accounts for $52 \%$ of deaths in patients with T2D and $44 \%$ in patients T1D. ${ }^{3-5}$

Hyperglycemia, among various other factors such as insulin resistance, contributes significantly to the pathogenesis of microvascular and macrovascular complications in diabetes. In addition to sustained hyperglycemia, swings in glucose concentration or GV have been associated with increased rate of microvascular complications. Data from the Diabetes Complications Control Trial clearly showed the positive relationship between higher HbA1c levels and GV and rate of complications. ${ }^{43}$ In that study, for every increase in SD of HbAlc by absolute $1 \%$, the HR of both the development and progression of retinopathy increased by more than $100 \%$ (HR 2.26 for every absolute $1 \%$ increase in HbA1c SD, 95\% CI 1.63 to 3.14). ${ }^{334344}$ More recently, several longitudinal studies in patients with T1D and T2D have confirmed that patients in higher quartiles of HbA1c have increased risk of proliferative retinopathy compared with those in lower quartiles. ${ }^{334344}$ The risk of nephropathy and albuminuria has also been shown to be remarkably increased (up to 80\%) for each increase in SD. ${ }^{43}$ In addition, high GV has been shown to increase the risk of peripheral and cardiac autonomic neuropathy. ${ }^{194}$

A large body of evidence has pointed to the relationship between GV and hypoglycemia, with hypoglycemia being more common in patients with increased GV. ${ }^{13}$ This risk is increased when the mean blood glucose concentration is low or if deviations around the mean glucose concentrations are large, suggesting the need to reduce short-term $\mathrm{GV}^{46}$ This association is more pronounced in patients receiving insulin treatment. In a pooled analysis of six randomized controlled trials of 1699 insulin-treated adult patients with T2D, all measures of GV were significantly associated with on-trial development of hypoglycemia. ${ }^{45}$ Hypoglycemia, however, is not restricted to insulin use. Sulfonylureas are also associated with increased risk of hypoglycemia, particularly in older patients and those with renal impairment. The frequency of hypoglycemic events in patients with T2D treated with insulin or oral antidiabetic agents increased significantly when the GV exceeded the mean SD value. In a mixed population of people with T2D, the incidence of hypoglycemic events was three to six times greater in patients with a within-day CV of more than 36\% compared with a CV less than $36 \%$, irrespective of the type of treatment 
Table 1 Studies assessing the impact of GV on cardiovascular outcomes in patients with T2D

\begin{tabular}{|c|c|c|c|c|c|}
\hline Study & $\begin{array}{l}\text { Patients, } \\
\text { population }\end{array}$ & $\begin{array}{l}\text { Follow-up } \\
\text { (months) }\end{array}$ & $\begin{array}{l}\text { GV measure, } \\
\text { metrics }\end{array}$ & Outcomes & Results \\
\hline $\begin{array}{l}\text { ADVANCE } \\
\text { Hirakawa et }\left.a\right|^{21}\end{array}$ & 4399, T2D & 24 & $\begin{array}{l}\mathrm{FG} \text { and } \mathrm{HbA1c} \\
\text { visit-to-visit } \\
\text { variation } \\
\text { (CV) }\end{array}$ & $\begin{array}{l}\text { Combined macrovascular } \\
\text { and microvascular events } \\
\text { and all-cause mortality }\end{array}$ & $\begin{array}{l}\text { Increased HbA1c visit-to-visit variation was } \\
\text { associated with increased risk of vascular events } \\
(p=0.01, H R 1.64,1.05-2.55) \text {, macrovascular } \\
\text { events }(p=0.02) \text {, and mortality }(p<0.001, H R 3.31 \text {, } \\
1.57-6.98) \text {. } \\
\text { FG visit-to-visit variation was associated with } \\
\text { increased risk of CV events ( } p<0.001, H R 2.70 \text {, } \\
1.65-4.42) \text { and macrovascular ( } p=0.005) \text { and } \\
\text { microvascular ( } p<0.001 \text { ) events. }\end{array}$ \\
\hline $\begin{array}{l}\text { DEVOTE } 2 \\
\text { Zinman et } a l^{49}\end{array}$ & 7586, T2D & 24 & $\begin{array}{l}\text { SMBG } \\
\text { (SD) }\end{array}$ & $\begin{array}{l}\text { MACE, severe } \\
\text { hypoglycemia }\end{array}$ & $\begin{array}{l}\text { GV was associated with severe hypoglycemia: HR } \\
4.11 \text { (3.15-5.35); MACE: HR } 1.36 \text { (1.12-1.65); and } \\
\text { all cause mortality: HR } 1.58 \text { (1.23-2.03). }\end{array}$ \\
\hline Takahashi et a $\left.\right|^{50}$ & 417, ACS & 39 & $\begin{array}{l}\text { CGM } \\
\text { (MAGE) }\end{array}$ & MACCE & $\begin{array}{l}\text { MAGE was associated with increased MACCE } \\
(23.5 \% \text { vs } 11.6 \%, p=0.002) \text { and was an } \\
\text { independent predictor of poor prognosis }(p=0.045 \text {, } \\
\text { HR } 1.84,1.01-3.36) \text {. }\end{array}$ \\
\hline Gerbaud et al ${ }^{42}$ & 327, ACS & 16.9 & $\begin{array}{l}\text { SMBG } \\
\text { (SD) }\end{array}$ & MACE & $\begin{array}{l}\text { GV cut-off of }>2.70 \mathrm{mmol} / \mathrm{L} \text { was the strongest } \\
\text { independent predictive factor of MACE: OR } 2.21 \\
(1.64-0.98), p<0.001 \text {. }\end{array}$ \\
\hline $\begin{array}{l}\text { VADT } \\
\text { Zhou et }\left.a\right|^{51}\end{array}$ & 1791, T2D & 84 & $\begin{array}{l}\mathrm{FG} \text { and } \mathrm{HbA} 1 \mathrm{c} \\
\text { (CV, ARV) }\end{array}$ & MACCE & $\begin{array}{l}\text { CV and ARV of FG were significantly associated } \\
\text { with CVD: CV glucose: } p=0.003 \text {, OR } 1.162 \\
(1.054-1.281) \text {; ARV glucose: } p=0.0006 \text {, OR } 1.168 \\
(1.069-1.275) \text {. }\end{array}$ \\
\hline $\begin{array}{l}\text { HEART2D } \\
\text { Siegelaar et }\left.a\right|^{52}\end{array}$ & 1115, AMI & 42 & $\begin{array}{l}\text { SMBG } \\
\text { (MAGE, MAG, } \\
\text { SD) }\end{array}$ & MACCE & $\begin{array}{l}\text { No association between GV and CVD. } \\
\text { MAG } p=0.57 \text {, MAGE } p=0.49 \text { and SD } p=0.52 \text {. }\end{array}$ \\
\hline
\end{tabular}

\begin{tabular}{|c|c|c|}
\hline $\begin{array}{l}\text { DIGAMI } 2 \\
\text { Mellbin et }\left.a\right|^{53}\end{array}$ & $578, \mathrm{AMI}$ & 12 \\
\hline
\end{tabular}

No association between GV and complications. Composite endpoint: RMSE p=0.28, HR $1.09(0.93-$ 1.27), mortality $\mathrm{p}=0.21$, HR $1.14(0.93-1.38)$.

ACS, acute coronary syndrome; ADVANCE, Action in Diabetes and Vascular Disease; AMI, acute myocardial infarction; ARV, average real variability; BG, blood glucose; CGM, continuous glucose monitoring; CV, coefficient of variation; CVD, cardiovascular disease; DEVOTE 2, Degludec vs Insulin Glargine in Patients with Type 2 Diabetes at High Risk of Cardiovascular Events; DIGAMI 2, Diabetes Mellitus, Insulin Glucose Infusion in Acute Myocardial Infarction; FG, fasting glucose; GV, glycemic variability; HbA1c, glycated hemoglobin; HEART2D, Hyperglycemia and Its Effect after Acute Myocardial Infarction on Cardiovascular Outcomes in Patients with Type 2 Diabetes Mellitus; MACCE, mayor adverse cardiovascular and cerebrovascular events; MACE, mayor adverse cardiovascular events; MAG, mean absolute glucose; MAGE, mean amplitude of glycemic excursions; RMSE, root mean square error; SMBG, self-monitored blood glucose; T2D, type 2 diabetes; VADT, Veteran Affairs Diabetes Trial.

with oral diabetes drugs or insulin. ${ }^{47}$ Similarly, in a shortterm study (4 weeks) using CGM in 231 subjects with T2D without insulin therapy treated with oral hypoglycemic agents including sulfonylureas, a higher $\mathrm{CV}>40 \%$ was significantly associated with a glucose level of $<70 \mathrm{mg} /$ dL. ${ }^{16}$

\section{GV and cardiovascular disease}

Sustained hyperglycemia measured by high HbAlc or by CGM and increased GV are important factors associated with cardiovascular outcomes in patients with T2D. ${ }^{21} 3448$ Clinical studies and meta-analyses have shown that GV is positively associated with macrovascular complications and mortality (table 1), independently of the HbAlc level. A meta-analysis by Gorst $e t a t^{20}$ reported the association between $\mathrm{HbAlc}$ variability and microvascular and macrovascular complications and mortality. High HbA1c variability among patients with T1D was associated with increased risk of renal disease (risk ratio 1.56, $95 \%$ CI 1.08 to 2.25$)$, cardiovascular events $(1.98,1.39$ to $2.82)$, and retinopathy $(2.11,1.54$ to 2.89$)$. In the same meta-analysis were included 13 studies of patients with T2D, where higher HbA1c variability was associated with higher risk of renal disease (1.34, 1.15 to 1.57$)$, macrovascular events (1.21, 1.06 to 1.38$)$, ulceration/gangrene $(1.50,1.06$ to 2.12$)$, cardiovascular disease $(1.27,1.15$ to 1.40$)$, and mortality $(1.34,1.18$ to 1.53$) .{ }^{20}$ A post-hoc analysis of the ADVANCE (Action in Diabetes and Vascular Disease) clinical trial ${ }^{21}$ reported on the effect of visit-to-visit variability in $\mathrm{HbAlc}$ and fasting glucose every 3 months for 24 months on major adverse cardiovascular events (MACE) — death from cardiovascular causes, non-fatal myocardial infarction or non-fatal stroke-in patients with T2D. They found that fasting GV was associated with both macrovascular and microvascular events and that HbAlc variability was positively associated with risk of macrovascular events. ${ }^{21}$

Similarly, DEVOTE 2 (Degludec vs Insulin Glargine in Patients with Type 2 Diabetes at High Risk of Cardiovascular Events ${ }^{49}$ analyzed day-to-day fasting GV in patients with T2D at high risk of cardiovascular events, based on 
the SD of the 3-day SMBG before visit each month. This study reported on the associations of day-to-day fasting GV by SMBG with severe hypoglycemia and cardiovascular outcomes. High day-to-day fasting GV was significantly associated with severe hypoglycemia, MACE and all-cause mortality; risks raised 2.7-fold, 1.2-fold and 1.4fold, respectively, when fasting GV was duplicated. ${ }^{49}$

Several recent studies have investigated the influence of GV on prognosis and predictor of cardiovascular disease in patients with acute coronary syndrome. Takahashi $e t a \tilde{l}^{0}$ explored the effect of GV on the incidence of major adverse cardiovascular and in patients with acute coronary syndrome who underwent percutaneous coronary intervention. Patients wore a CGM system from admission with a mean period of follow-up of 39 months. They reported that GV was an independent predictive factor of poor prognosis, with the high GV group having significantly lower event-free survival rates. Gerbaud $e t$ $a l^{42}$ reported that in patients with diabetes and acute coronary syndrome, a GV cut-off value of $>2.70 \mathrm{mmol} / \mathrm{L}$ $(49 \mathrm{mg} / \mathrm{dL})$ was the strongest independent predictive factor of MACE, including new onset of myocardial infarction, acute heart failure and cardiac death.

A post-hoc analysis of the Veteran Affairs Diabetes Trial investigated the association between GV by fasting glucose and HbAlc with cardiovascular disease. ${ }^{51}$ This study measured long-term GV in 1791 individuals by $\mathrm{CV}$ and average real variability for fasting glucose and HbAlc taken every 3 months for up to 84 months. The results showed a significant association between variability of fasting glucose and cardiovascular disease even after adjusting for different risk factors, including mean fasting glucose. Conversely, the association was not present for HbAlc variability.

Despite most studies reporting a positive relationship, some publications have reported lack of association between GV and cardiovascular disease. The HEART2D study (Hyperglycemia and Its Effect after Acute Myocardial Infarction on Cardiovascular Outcomes in Patients with Type 2 Diabetes Mellitus) reported no difference in GV in patients who experienced cardiovascular events and those without events. ${ }^{52}$ This trial investigated differences between two insulin treatment strategies on time until first combined cardiovascular event (a composite of cardiovascular death, non-fatal myocardial infarction, non-fatal stroke, coronary revascularization or hospitalization for acute coronary syndrome) in patients with recent acute myocardial infarction. An analysis to assess the effect of intraday GV from 7-point SMBG reported no difference on cardiovascular outcomes despite reduced intraday GV and postprandial hyperglycemia. ${ }^{52}$ Similarly, the DIGAMI 2 study (Diabetes Mellitus, Insulin Glucose Infusion in Acute Myocardial Infarction) reported no relationship between GV and acute cardiovascular complications in 578 patients with T2D. ${ }^{53}$ The authors reported lack of association between GV during the initial phase during hospitalization or in the composite of mortality, non-fatal stroke and reinfarction after
1 year of follow-up. ${ }^{52}$ Furthermore, the FLAT-SUGAR trial $^{54}$ compared the effect of rapid-acting insulin with a glucagon-like peptide 1 receptor agonist (GLP-1RA) on GV in patients treated with basal insulin. They reported that GLP1-RA resulted in significant reductions in GV determined by CGM compared with prandial insulin. Despite the improvement in GV, there was no statistically significant difference in cardiac arrhythmias, cardiovascular risk biomarkers or severe hypoglycemia events.

\section{CONCLUSIONS}

GV is defined by the measurement of fluctuations in glycemic metrics, either short-term (within-day and between-day variability) or long-term GV, which is usually based on serial measurements over a longer period of time, usually involving $\mathrm{HbAlc}$ as well as fasting and postprandial plasma glucose values. During the past three decades, HbA1c, a measure of sustained hyperglycemia, has been the main target to assess response to diabetes treatment based on the positive association between poor glycemic control and acute and long-term complications of diabetes, and that reduction in HbA1c leads to lower rates in diabetic complications. In recent years, increasing information indicates that short-term and long-term glycemic fluctuations have greater deleterious effects on the development of diabetic complications. The results of experimental and clinical studies demonstrate that glucose fluctuations are associated with oxidative stress, endothelial dysfunction, and inflammation, factors traditionally associated with the pathogenesis of microvascular and macrovascular diseases. However, clear data confirming GV as an independent risk factor of diabetic complications are still lacking. Therefore, in clinical practice, a global antidiabetic strategy should be aimed at reducing to a minimum the different components of dysglycemia, including HbA1c, fasting and postprandial glucose, as well as GV.

By providing frequent blood glucose concentration measurements in a continuous-time fashion, minimally invasive CGM sensors are becoming an increasingly adopted technology for the management of patients with T1D and T2D. ${ }^{55}$ By providing real-time information on glucose concentration and trend, CGM sensors have been shown to improve glycemic control, reduce hypoglycemia incidence, and decrease GV. A recent consensus conference suggested that relevant CGM data should include not only glucose levels but also various glucose metrics such as TIR, patterns of hypoglycemia and hyperglycemia, and GV. Future prospective randomized clinical trials using CGM devices are needed to evaluate the role of GV in the development of cardiovascular complications in patients with diabetes.

Contributors All authors contributed to literature review and manuscript writing

Funding GEU is partially supported by the National Institutes of Health grants (UL1TR002378-04 and 1P30DK111024-05) and has received unrestricted research support for inpatient studies (to Emory University) from Dexcom, Novo Nordisk, and AstraZeneca. 
Competing interests None declared.

Patient consent for publication Not required.

Provenance and peer review Commissioned; externally peer reviewed.

Data availability statement № data are available.

Open access This is an open access article distributed in accordance with the Creative Commons Attribution Non Commercial (CC BY-NC 4.0) license, which permits others to distribute, remix, adapt, build upon this work non-commercially, and license their derivative works on different terms, provided the original work is properly cited, appropriate credit is given, any changes made indicated, and the use is non-commercial. See: http://creativecommons.org/licenses/by-nc/4.0/.

ORCID ID

Guillermo E Umpierrez http://orcid.org/0000-0002-3252-5026

\section{REFERENCES}

1 International Diabetes Federation. IDF diabetes atlas teB, Belgium, 2019. Available: https://www.diabetesatlas.org

2 Chudleigh RA, Bain S. Cardiovascular safety of liraglutide for the treatment of type 2 diabetes. Expert Opin Drug Saf 2017;16:627-35.

3 Chan JCN, Lim L-L, Wareham NJ, et al. The Lancet Commission on diabetes: using data to transform diabetes care and patient lives. Lancet 2021;396:2019-82.

4 Huang D, Refaat M, Mohammedi K, et al. Macrovascular complications in patients with diabetes and prediabetes. Biomed Res Int 2017;2017:1-9.

5 Morrish NJ, Wang SL, Stevens LK, et al. Mortality and causes of death in the who multinational study of vascular disease in diabetes. Diabetologia 2001;44 Suppl 2:S14-21.

6 Nathan DM, Cleary PA, Backlund J-YC, et al. Intensive diabetes treatment and cardiovascular disease in patients with type 1 diabetes. N Engl J Med 2005;353:2643-53.

7 ADVANCE Collaborative Group, Patel A, MacMahon S, et al. Intensive blood glucose control and vascular outcomes in patients with type 2 diabetes. N Engl J Med 2008;358:2560-72.

8 Duckworth W, Abraira C, Moritz T, et al. Glucose control and vascular complications in veterans with type 2 diabetes. $N$ Engl $J$ Med 2009;360:129-39.

9 ACCORD Study Group, Gerstein HC, Miller ME, et al. Long-term effects of intensive glucose lowering on cardiovascular outcomes. $N$ Engl J Med 2011;364:818-28.

10 American Diabetes Association. 10. cardiovascular disease and risk management: standards of medical care in diabetes-2020. Diabetes Care 2020;43:S111-34.

11 American Diabetes Association. 9. pharmacologic approaches to glycemic treatment: standards of medical care in diabetes-2020. Diabetes Care 2020;43:S98-110.

12 Garber AJ, Handelsman Y, Grunberger G, et al. Consensus statement by the American association of clinical endocrinologists and American college of endocrinology on the comprehensive type 2 diabetes management algorithm - 2020 executive summary. Endocr Pract 2020;26:107-39.

13 Umpierrez GE, P Kovatchev B. Glycemic variability: how to measure and its clinical implication for type 2 diabetes. Am J Med Sci 2018;356:518-27.

14 Qu Y, Jacober SJ, Zhang Q, et al. Rate of hypoglycemia in insulintreated patients with type 2 diabetes can be predicted from glycemic variability data. Diabetes Technol Ther 2012;14:1008-12.

15 Siegelaar SE, Holleman F, Hoekstra JBL, et al. Glucose variability; does it matter? Endocr Rev 2010;31:171-82.

$16 \mathrm{Jin}$ S-M, Kim T-H, Bae JC, et al. Clinical factors associated with absolute and relative measures of glycemic variability determined by continuous glucose monitoring: an analysis of 480 subjects. Diabetes Res Clin Pract 2014;104:266-72.

17 Penckofer S, Quinn L, Byrn M, et al. Does glycemic variability impact mood and quality of life? Diabetes Technol Ther 2012;14:303-10.

18 Di Flaviani A, Picconi F, Di Stefano P, et al. Impact of glycemic and blood pressure variability on surrogate measures of cardiovascular outcomes in type 2 diabetic patients. Diabetes Care 2011;34:1605-9.

19 Ceriello A, Monnier L, Owens D. Glycaemic variability in diabetes: clinical and therapeutic implications. Lancet Diabetes Endocrinol 2019;7:221-30.

20 Gorst C, Kwok CS, Aslam S, et al. Long-term glycemic variability and risk of adverse outcomes: a systematic review and metaanalysis. Diabetes Care 2015;38:2354-69.
21 Hirakawa Y, Arima H, Zoungas S, et al. Impact of visit-to-visit glycemic variability on the risks of macrovascular and microvascular events and all-cause mortality in type 2 diabetes: the advance trial. Diabetes Care 2014;37:2359-65.

22 Kaze AD, Santhanam P, Erqou S, et al. Long-term variability of glycemic markers and risk of all-cause mortality in type 2 diabetes: the look ahead study. BMJ Open Diabetes Res Care 2020;8:e001753.

23 Scott ES, Januszewski AS, O'Connell R, et al. Long-term glycemic variability and vascular complications in type 2 diabetes: post hoc analysis of the field study. J Clin Endocrinol Metab 2020;10510.1210/clinem/dgaa361. [Epub ahead of print: 01 Oct 2020].

24 Quagliaro L, Piconi L, Assaloni R, et al. Intermittent high glucose enhances ICAM-1, VCAM-1 and E-selectin expression in human umbilical vein endothelial cells in culture: the distinct role of protein kinase $\mathrm{C}$ and mitochondrial superoxide production. Atherosclerosis 2005;183:259-67.

25 Echouffo-Tcheugui JB, Zhao S, Brock G, et al. Visit-to-visit glycemic variability and risks of cardiovascular events and all-cause mortality: the ALLHAT study. Diabetes Care 2019;42:486-93.

26 Kovatchev BP. Metrics for glycaemic control - from $\mathrm{HbA}_{1 \mathrm{c}}$ to continuous glucose monitoring. Nat Rev Endocrinol 2017;13:425-36.

27 Service FJ. Glucose variability. Diabetes 2013;62:1398-404.

28 Clarke SF, Foster JR. A history of blood glucose meters and their role in self-monitoring of diabetes mellitus. $\mathrm{Br} \mathrm{J}$ Biomed Sci 2012;69:83-93.

29 Cappon G, Vettoretti M, Sparacino G, et al. Continuous glucose monitoring sensors for diabetes management: a review of technologies and applications. Diabetes Metab J 2019;43:383-97.

30 Agiostratidou G, Anhalt H, Ball D, et al. Standardizing clinically meaningful outcome measures beyond $\mathrm{HbA}_{1 \mathrm{c}}$ for type 1 diabetes: a consensus report of the american Association of clinical endocrinologists, the American association of diabetes educators, the American diabetes association, the endocrine society, JDRF International, the Leona M. and Harry B. Helmsley charitable trust, the pediatric endocrine society, and the T1D exchange. Diabetes Care 2017;40:1622-30.

31 Nalysnyk L, Hernandez-Medina M, Krishnarajah G. Glycaemic variability and complications in patients with diabetes mellitus: evidence from a systematic review of the literature. Diabetes Obes Metab 2010;12:288-98.

$32 \mathrm{Lu} \mathrm{J}, \mathrm{Ma} X$, Zhou J, et al. Association of time in range, as assessed by continuous glucose monitoring, with diabetic retinopathy in type 2 diabetes. Diabetes Care 2018;41:2370-6.

33 Hermann JM, Hammes H-P, Rami-Merhar B, et al. Hba1C variability as an independent risk factor for diabetic retinopathy in type 1 diabetes: a German/Austrian multicenter analysis on 35,891 patients. PLoS One 2014;9:e91137.

34 Nusca A, Tuccinardi D, Albano M, et al. Glycemic variability in the development of cardiovascular complications in diabetes. Diabetes Metab Res Rev 2018;34:e3047.

35 Picconi F, Di Flaviani A, Malandrucco I, et al. Impact of glycemic variability on cardiovascular outcomes beyond glycated hemoglobin. Evidence and clinical perspectives. Nutr Metab Cardiovasc Dis 2012;22:691-6.

36 Battelino T, Danne T, Bergenstal RM, et al. Clinical targets for continuous glucose monitoring data interpretation: recommendations from the International consensus on time in range. Diabetes Care 2019;42:1593-603.

37 Danne T, Nimri R, Battelino T, et al. International consensus on use of continuous glucose monitoring. Diabetes Care 2017;40:1631-40.

38 Paneni F, Beckman JA, Creager MA, et al. Diabetes and vascular disease: pathophysiology, clinical consequences, and medical therapy: Part I. Eur Heart J 2013;34:2436-43.

39 Cosentino-Gomes D, Rocco-Machado N, Meyer-Fernandes JR. Cell signaling through protein kinase $\mathrm{C}$ oxidation and activation. Int $\mathrm{J} \mathrm{Mol}$ Sci 2012;13:10697-721.

40 Giacco F, Brownlee M. Oxidative stress and diabetic complications. Circ Res 2010;107:1058-70.

41 Ying C, Liu T, Ling H, et al. Glucose variability aggravates cardiac fibrosis by altering Akt signalling path. Diab Vasc Dis Res 2017;14:327-35.

42 Gerbaud E, Darier R, Montaudon M, et al. Glycemic variability is a powerful independent predictive factor of midterm major adverse cardiac events in patients with diabetes with acute coronary syndrome. Diabetes Care 2019;42:674-81.

43 Kilpatrick ES, Rigby AS, Atkin SL. A1C variability and the risk of microvascular complications in type 1 diabetes: data from the diabetes control and complications trial. Diabetes Care 2008;31:2198-202. 
44 Akaza M, Akaza I, Kanouchi T, et al. Nerve conduction study of the association between glycemic variability and diabetes neuropathy. Diabetol Metab Syndr 2018;10:69.

45 Kovatchev B, Umpierrez G, DiGenio A, et al. Sensitivity of traditional and Risk-Based glycemic variability measures to the effect of glucose-lowering treatment in type 2 diabetes mellitus. J Diabetes Sci Technol 2015;9:1227-35.

46 Ceriello A, Ihnat MA. 'Glycaemic variability': a new therapeutic challenge in diabetes and the critical care setting. Diabet Med 2010;27:862-7.

47 Monnier L, Colette C, Wojtusciszyn A, et al. Toward defining the threshold between low and high glucose variability in diabetes. Diabetes Care 2017;40:832-8.

48 Schejter YD, Turvall E, Ackerman Z. Characteristics of patients with sulphonurea-induced hypoglycemia. J Am Med Dir Assoc 2012;13:234-8.

49 Zinman B, Marso SP, Poulter NR, et al. Day-to-day fasting glycaemic variability in DEVOTE: associations with severe hypoglycaemia and cardiovascular outcomes (DEVOTE 2). Diabetologia 2018;61:48-57.

50 Takahashi H, Iwahashi N, Kirigaya J, et al. Glycemic variability determined with a continuous glucose monitoring system can predict prognosis after acute coronary syndrome. Cardiovasc Diabetol 2018;17:116.

51 Zhou JJ, Schwenke DC, Bahn G, et al. Glycemic variation and cardiovascular risk in the Veterans Affairs diabetes trial. Diabetes Care 2018;41:2187-94.

52 Siegelaar SE, Kerr L, Jacober SJ, et al. A decrease in glucose variability does not reduce cardiovascular event rates in type 2 diabetic patients after acute myocardial infarction: a reanalysis of the HEART2D study. Diabetes Care 2011;34:855-7.

53 Mellbin LG, Malmberg K, Rydén L, et al. The relationship between glycaemic variability and cardiovascular complications in patients with acute myocardial infarction and type 2 diabetes: a report from the DIGAMI 2 trial. Eur Heart J 2013;34:374-9.

54 FLAT-SUGAR Trial Investigators. Glucose variability in a 26-week randomized comparison of mealtime treatment with rapid-acting insulin versus GLP-1 agonist in participants with type 2 diabetes at high cardiovascular risk. Diabetes Care 2016;39:973-81.

55 Rodbard D. Continuous glucose monitoring: a review of recent studies demonstrating improved glycemic outcomes. Diabetes Technol Ther 2017;19:S-25-S-37. 